\title{
The microbiology and clinical characteristics of bacterial and fungal meningitis in a Chinese hospital
}

Wei Chen ${ }^{1}$, Qian Hu², Wen En Liu ${ }^{1}$

${ }^{1}$ Department of Clinical Laboratory, Xiangya Hospital of Central South University, Changsha, China

2Department of Laboratory Medical Science, Hunan Normal University of Medicine, Changsha, China

Submitted: 29 May 2017

Accepted: 2 July 2017

Arch Med Sci Civil Dis 2016; 1: e99-e109

DOI: https://doi.org/10.5114/amscd.2017.69379

Copyright $\odot 2017$ Termedia \& Banach

\section{Abstract}

Introduction: The aim was to investigate the distribution, antibiotic resistance, initial clinical and laboratory characteristics of pathogens isolated from the cerebrospinal fluid samples (CSF).

Material and methods: The CSF were subjected for identification. The minimum inhibitory concentrations (MICs) of antimicrobial agents were tested. The initial clinical and laboratory characteristics were collected.

Results: The rate of positive yield of pathogen meningitis in our study was $8.16 \%$. Among the 1994 non-repetitive pathogens, Gram-positive pathogen was the most common $(71.71 \%)$, followed by Gram-negative pathogen (20.36\%), fungal (6.62\%) and Mycobacterium tuberculosis (1.30\%). Coagulase-negative staphylococci (CNS) was the most common Gram-positive pathogen and Acinetobacter baumannii (Ab) was the most common Gram-negative pathogen. As to fungal pathogen, Cryptococcus neoformans (CN) was the most common. The main CNS showed higher antimicrobial resistant rate for Penicillin G, oxacillin, clindamycin and erythromycin. Acinetobacter baumannii resistant to the most tested antibiotics and only showed considerable rate of resistance to cefoperazone/sulbactam, tigecycline and amikacin. All CN were susceptible to 5-fluorocytosine and only $3.6 \% \mathrm{CN}$ were resistance to fluconazole. Long days of hospital stay, fever and meningeal irritation signs were common symptoms in the bacterial and fungal meningitis. Head injury, disturbance of consciousness, the pupil size of both eyes was not equal, pupillary reaction to light was slow or absent were more common in the Ab meningitis. The CSF protein concentration and white blood cells count as well as glucose concentration can be used in guiding initial treatment and further microbiological investigation.

Conclusions: The main pathogens showed higher antimicrobial resistant rate and the selection of empiric antibiotics should take into consideration local epidemiology, antibiotic resistance patterns and the suspected causative microorganism.

Key words: cerebrospinal fluid, central nervous system infections, bacterial meningitis, fungal meningitis, drug resistance, clinical characteristics.

\section{Introduction}

Bacterial and fungal meningitis, an infection of the meninges and cerebrospinal fluid surrounding the brain and spinal cord, is a serious threat to global health. Bacterial meningitis kills about a fifth of people

\author{
Corresponding author: \\ Wei Chen \\ Department of \\ Clinical Laboratory \\ Xiangya Hospital of \\ Central South University \\ 410008 Changsha, China \\ Phone: 186-13627317343 \\ E-mail: 573570494@qq.com
}


with the disease and up to half of the survivors suffer debilitating sequelae $[1,2]$. It is a major cause of death and disability worldwide [3].

The main pathogens of bacterial and fungal meningitis are known to be different in different eras and geographic areas [4, 5]. Epidemiologic trends between western and eastern countries appear to differ in the percentage contributions of the major species inducing bacterial and fungal meningitis. In surveys from western countries, Escherichia coli was the leading pathogen among aerobic Gram-negative bacilli, which account for $4.3-12.3 \%$ of the pathogens causing bacterial meningitis [6]. In Asia, Klebsiella pneumoniae was the most common among the implicated Gram-negative pathogens and the overall incidence of meningitis caused by Gram-negative bacilli is $7.6-28.8 \%[6,7]$, which is about twice the incidence in western countries.

To reduce the mortality and improve the cure rates, it is vital to screen and identify pathogens in clinical specimens from patients as early as possible $[8,9]$. Early and accurate diagnosis will support physicians with the selection of the appropriate antimicrobial agents [10]. Most laboratory methods are mainly based on the identification of pathogens by staining or cultures, the detection of specific antigens and antibodies, or the examination of pathogen nucleic acids with polymerase chain reaction (PCR) in CSF $[11,12]$. Although diagnosis based on culture is the gold standard for the diagnosis of bacterial and fungal meningitis, the clinical value of culture technique is limited due to its low sensitivity and long time required [13]. Early clinical suspicion and implementation of appropriate antimicrobial therapy are critical to minimize adverse outcomes. The decision to commence antibiotics is often based on clinical symptoms as well as on the preliminary laboratory results, which are readily available within an hour. The initial clinical and laboratory characteristics of patients can guide initial treatment and further microbiological investigation.

In spite of the harm caused by bacterial and fungal meningitis, the contribution of pathogens to meningitis remains poorly described in many regions of the various developing countries [14]. So we conducted the present study to investigate the frequency and antibiotic resistance of pathogens isolated from the cerebrospinal fluid samples (CSF) of patients admitted to Xiangya Hospital of Central South University with suspected meningitis and analyze the clinical and laboratory characteristics of bacterial and fungal meningitis to determine the utility of clinical and laboratory parameters in assessing the suspected causative microorganism.

\section{Material and methods}

\section{Patients}

This study was conducted at Xiangya Hospital of Central South University, a 3500-bed tertiary care facility with an annual admission of more than 100,000 inpatients, located in Hunan, China. Only the first strain isolated from CSF was collected when duplicate strains were from the same patient from 2012 to 2016. All isolates were identified to the species level by the Vitek-2 Compact system (bioMerieux, Durham, NC). The MICs of antimicrobial agents were determined by Vitek AST-GN13, AST-GN16 or AST-GP cards (bioMerieux, Durham, NC) for bacterial and by ATB FUNGUS 3 (bioMerieux, Durham, NC) for fungi. The results were interpreted according to the breakpoints recommended by the Clinical and Laboratory Standards Institute (CLSI, 2016) [15]. Staphylococcus aureus ATCC29213, Escherichia coli ATCC25922 and Pseudomonas aeruginosa ATCC27853 were used as a quality control strain.

\section{Data collection}

Clinical information was obtained by reviewing patients' medical charts. The clinical data collected in the study included sex, age, days of hospital stay, head injury before hospitalization, invasive operation in brain, underlying diseases (diabetes, hypertension, chronic pulmonary disease, neurologic disease and chronic liver disease), bacteremia, the main clinical manifestations (fever, headache, nausea/vomiting, meningeal irritation signs, disturbance of consciousness, the pupil size of both eyes not being equal, pupillary reaction to light being slow or absent, twitch), the prescribed antimicrobial/immunosuppressant/hormone received within 7 days prior to positive culture of pathogen, laboratory results including CSF white blood cells (WBC) count and classification, CSF glucose concentration, CSF protein concentration, peripheral WBC and platelet count. Laboratory data were taken on the day of the first strain isolated from the CSF. This study was approved by the Xiangya Hospital Ethics Committee.

\section{Statistical analysis}

All the results were analyzed by the statistical package for social science software (version 20.0; SPSS, Chicago, IL, USA). Numerical variables with normal distribution were presented as the mean \pm standard deviation $(x \pm \mathrm{SD})$, and those without normal distribution were described as the median with range. Categorical variables were presented as the frequency (percentage). One-way ANOVA and least significant difference (LSD) t-test were used to compare continuous variables as appropriate. $\chi^{2}$ test and $\chi^{2}$ segmentation were used 
to compare categorical variables as appropriate. A $p$-value of less than 0.05 was considered statistically significant (except for $\chi^{2}$ segmentation), and all probabilities were two tailed.

\section{Results}

\section{Distribution of pathogens in cerebrospinal} fluid samples

A total of 1994 non-repetitive pathogens were isolated from 24423 CSF samples obtained at the Xiangya Hospital of Central South University during 2012-2016 over a period of 5 years. The rate of positive yield of pathogen meningitis in our study was $8.16 \%$ (1994/24423). Most strains were identified from neurosurgery, neurology and intensive care unit (ICU). Men accounted for $64.0 \%$ of all patients, and the median age was 42 years (range: 0-81 years). Among the 1994 non-repetitive pathogens found in the CSF, Gram-positive pathogens were the most common (1430, 71.71\%), followed by Gram-negative pathogens (406, 20.36\%), fungal (132, 6.62\%) and Mycobacterium tuberculosis $(26,1.30 \%)$. As to the Gram-positive pathogen, central nervous system (CNS) was the most common, followed by Streptococcus pneumoniae, Enterococcus faecium, Corynebacterium and Staphylococcus aureus (SA). As to the Gram-negative pathogens, $\mathrm{Ab}$ was the most common, followed by Klebsiella pneumoniae (Kp), Escherichia coli (Ec), other Acinetobacter and Pseudomonas aeruginosa (PA). As to the fungal pathogens, CN was the most common, followed by Candida albicans (Table I).

\section{Antibiotic resistance rate of the main pathogens}

\section{Antibiotic resistance rate of the major Staphylococcus}

Among the various antibiotics tested, linezolid, vancomycin, Quinupristin/Dalfopristin syncercid, tigecycline and nitrofurantoin were found most effective against the major Staphylococcus. The major Staphylococcus showed a higher antimicrobial resistant rate for penicillin G, oxacillin, clindamycin and erythromycin (Table II).

\section{Antibiotic resistance rate of the \\ Streptococcus pneumonia}

Among the various antibiotics tested, linezolid, vancomycin, ofloxacin, meropenem and ertapenem were found most effective against Streptococcus pneumoniae. Streptococcus pneumoniae showed a higher antimicrobial resistant rate for penicillin, erythromycin, tetracycline, clindamycin, trimethoprim/sulfamethoxazole and cefotaxime (Table III).

\section{Antibiotic resistance rate of Enterococcus faecium}

Among the various antibiotics tested, linezolid, vancomycin, Quinupristin/Dalfopristin syncercid and tigecyclinewerefound mosteffective against $E n$ terococcus faecium. Enterococcus faecium showed a higher antimicrobial resistant rate for penicillin G, ampicillin, erythromycin, tetracycline, ciprofloxacin and levofloxacin (Table IV).

\section{Antibiotic resistance rate of the major Gram-negative bacteria}

Ab was resistant to most tested antibiotics and only showed a considerable rate of resis-

Table I. Pathogen distribution of cerebrospinal fluid specimens

\begin{tabular}{|c|c|c|}
\hline Organisms & Number & Percentage \\
\hline Gram-positive bacteria: & 1430 & 71.72 \\
\hline $\begin{array}{l}\text { Coagulase-negative } \\
\text { staphylococci }\end{array}$ & 1016 & 50.95 \\
\hline Streptococcus pneumoniae & 115 & 5.77 \\
\hline Enterococcus faecium & 48 & 2.41 \\
\hline Corynebacterium & 48 & 2.41 \\
\hline Staphylococcus aureus & 40 & 2.01 \\
\hline Enterococcus faecalis & 38 & 1.91 \\
\hline Micrococcus lutea & 36 & 1.81 \\
\hline $\begin{array}{l}\text { Other Gram-positive } \\
\text { bacteria }\end{array}$ & 89 & 4.46 \\
\hline Gram-negative bacteria: & 406 & 20.36 \\
\hline Acinetobacter baumannii & 148 & 7.42 \\
\hline Other Acinetobacter & 31 & 1.55 \\
\hline Klebsiella pneumoniae & 47 & 2.36 \\
\hline Escherichia coli & 34 & 1.71 \\
\hline Pseudomonas aeruginosa & 26 & 1.30 \\
\hline Other Pseudomonas & 17 & 0.85 \\
\hline Bacillus genus & 17 & 0.85 \\
\hline $\begin{array}{l}\text { Other Gram-negative } \\
\text { bacteria }\end{array}$ & 86 & 4.31 \\
\hline Fungi and others: & 158 & 7.92 \\
\hline Cryptococcus neoformans & 92 & 4.61 \\
\hline Candida albicans & 22 & 1.10 \\
\hline Other fungi & 18 & 0.90 \\
\hline Mycobacterium tuberculosis & 26 & 1.30 \\
\hline Total & 1994 & 100.00 \\
\hline
\end{tabular}


Table II. Antibiotic resistance rate of the major Staphylococcus species

\begin{tabular}{|c|c|c|c|c|c|c|c|c|c|c|}
\hline \multirow[t]{2}{*}{ Antibiotic } & \multicolumn{2}{|c|}{$\begin{array}{c}\text { Staphylococcus } \\
\text { epidermidis }\end{array}$} & \multicolumn{2}{|c|}{$\begin{array}{l}\text { Staphylococcus } \\
\text { haemolyticus }\end{array}$} & \multicolumn{2}{|c|}{$\begin{array}{c}\text { Staphylococcus } \\
\text { capitis }\end{array}$} & \multicolumn{2}{|c|}{$\begin{array}{c}\text { Staphylococcus } \\
\text { hominis }\end{array}$} & \multicolumn{2}{|c|}{$\begin{array}{c}\text { Staphylococcus } \\
\text { aureus }\end{array}$} \\
\hline & $\mathrm{R}(\%)$ & I (\%) & R (\%) & I (\%) & R (\%) & I (\%) & $\mathrm{R}(\%)$ & I (\%) & R (\%) & I (\%) \\
\hline Penicillin G & 94.3 & 0.0 & 91.3 & 0.7 & 78.6 & 0.0 & 92.3 & 0.0 & 95.5 & 0.00 \\
\hline Oxacillin & 80.9 & 0.0 & 87.8 & 0.0 & 54.8 & 0.0 & 80.5 & 0.0 & 47.1 & 0.00 \\
\hline Gentamicin & 17.2 & 11.3 & 55.6 & 7.7 & 16.0 & 19.3 & 0.8 & 6.5 & 23.5 & 1.5 \\
\hline Rifampicin & 13.8 & 1.1 & 26.1 & 0.0 & 1.1 & 0.5 & 15.3 & 1.6 & 23.5 & 0.00 \\
\hline Ciprofloxacin & 33.7 & 8.3 & 76.1 & 4.9 & 41.1 & 98.5 & 48.0 & 2.4 & 29.9 & 0.00 \\
\hline Levofloxacin & 34.0 & 7.2 & 69.5 & 7.0 & 36.6 & 6.4 & 43.8 & 5.8 & 30.4 & 0.00 \\
\hline Moxifloxacin & 10.9 & 22.9 & 41.2 & 28.6 & 21.7 & 16.1 & 40.0 & 3.3 & 25.0 & 4.4 \\
\hline $\begin{array}{l}\text { Trimethoprim/ } \\
\text { sulfamethoxazole }\end{array}$ & 58.8 & 0.0 & 27.3 & 0.0 & 9.0 & 0.0 & 56.5 & 0.0 & 1.4 & 0.00 \\
\hline Clindamycin & 44.2 & 0.6 & 61.8 & 0.0 & 34.4 & 9.1 & 78.0 & 0.9 & 50.7 & 1.4 \\
\hline Erythromycin & 70.5 & 3.3 & 89.2 & 1.0 & 42.0 & 3.2 & 90.3 & 0.0 & 55.1 & 0.00 \\
\hline Linezolid & 0.0 & 0.0 & 0.7 & 0.0 & 1.8 & 0.0 & 0.0 & 0.0 & 0.00 & 0.00 \\
\hline Vancomycin & 0.0 & 0.2 & 0.0 & 0.0 & 0.0 & 0.0 & 0.0 & 0.0 & 0.00 & 0.00 \\
\hline $\begin{array}{l}\text { Quinupristin/ } \\
\text { Dalfopristin } \\
\text { syncercid }\end{array}$ & 0.0 & 0.0 & 0.0 & 0.0 & 0.0 & 0.0 & 1.3 & 0.0 & 0.00 & 0.00 \\
\hline Tetracycline & 29.6 & 1.0 & 26.7 & 0.5 & 6.4 & 2.2 & 37.3 & 0.4 & 39.7 & 0.00 \\
\hline Tigecycline & 0.0 & 0.0 & 0.0 & 0.0 & 0.0 & 0.0 & 0.0 & 0.0 & 0.00 & 0.00 \\
\hline Nitrofurantoin & 0.0 & 0.0 & 0.0 & 3.3 & 0.0 & 0.0 & 1.9 & 0.0 & 3.2 & 3.2 \\
\hline
\end{tabular}

Table III. Antibiotic resistance rate of Streptococcus pneumoniae

\begin{tabular}{|lccc|}
\hline Antibiotic & R (\%) & I (\%) & S (\%) \\
\hline Vancomycin & 0.00 & 0.00 & 100 \\
\hline Linezolid & 0.00 & 0.00 & 100 \\
\hline Ceftriaxone & 13.6 & 9.1 & 77.3 \\
\hline Levofloxacin & 12.9 & 0.00 & 87.1 \\
\hline Ofloxacin & 0.00 & 0.00 & 100 \\
\hline Meropenem & 0.00 & 0.00 & 100 \\
\hline Ertapenem & 0.00 & 11.8 & 88.2 \\
\hline Erythromycin & 86.5 & 2.7 & 10.8 \\
\hline Chloramphenicol & 12.0 & 0.00 & 88.0 \\
\hline Tetracycline & 80.0 & 0.00 & 20.0 \\
\hline Clindamycin & 95.2 & 0.00 & 4.8 \\
\hline Cefotaxime & 42.9 & 28.6 & 28.5 \\
\hline Penicillin & 71.4 & 0.00 & 28.6 \\
\hline Telithromycin & 5.9 & 0.00 & 94.1 \\
\hline $\begin{array}{l}\text { Trimethoprim/ } \\
\text { sulfamethoxazole }\end{array}$ & 66.7 & 7.4 & 25.9 \\
\hline
\end{tabular}

Table IV. Antibiotic resistance rate of Enterococcus faecium

\begin{tabular}{|lccc|}
\hline Antibiotic & R (\%) & I (\%) & S (\%) \\
\hline Ciprofloxacin & 83.9 & 12.9 & 3.2 \\
\hline Erythromycin & 88.7 & 9.7 & 1.6 \\
\hline Ampicillin & 89.1 & 0.0 & 10.9 \\
\hline Tetracycline & 67.2 & 0.0 & 32.8 \\
\hline Penicillin G & 85.5 & 0.0 & 14.5 \\
\hline $\begin{array}{l}\text { High } \\
\text { concentration } \\
\text { gentamicin }\end{array}$ & 22.7 & 0.0 & 77.3 \\
\hline Levofloxacin & 80.8 & 0.0 & 19.2 \\
\hline Clindamycin & $100^{\mathrm{a}}$ & 0.0 & 0.0 \\
\hline Linezolid & 0.0 & 0.0 & 100 \\
\hline Vancomycin & 3.1 & 6.3 & 90.6 \\
\hline Nitrofurantoin & 33.3 & 60.0 & 6.7 \\
\hline $\begin{array}{l}\text { Quinupristin/ } \\
\text { dalfopristin }\end{array}$ & 0.0 & 0.0 & 100 \\
\hline Tigecycline & 0.0 & 0.0 & 100 \\
\hline
\end{tabular}


Table V. Antibiotic resistance rate of the major Gram-negative bacteria

\begin{tabular}{|c|c|c|c|c|c|c|}
\hline \multirow[t]{2}{*}{ Antibiotic } & \multicolumn{2}{|c|}{ Acinetobacter baumannii } & \multicolumn{2}{|c|}{ Klebsiella pneumoniae } & \multicolumn{2}{|c|}{ Escherichia coli } \\
\hline & R (\%) & I (\%) & R (\%) & I (\%) & $\mathrm{R}(\%)$ & I (\%) \\
\hline Ampicillin & $100.0^{\mathrm{a}}$ & 0.0 & $100^{\mathrm{a}}$ & 0.00 & 96.6 & 0.00 \\
\hline Cefoperazone/sulbactam & 13.2 & 31.3 & 42.2 & 11.9 & 1.9 & 3.7 \\
\hline Piperacillin/tazobactam & 88.1 & 2.5 & 34.5 & 6.4 & 0.00 & 0.00 \\
\hline Aztreonam & $100^{\mathrm{a}}$ & 0.0 & 71.3 & 0.00 & 55.2 & 0.00 \\
\hline Ampicillin/sulbactam & 85.2 & 4.3 & 73.5 & 3.1 & 78.4 & 13.7 \\
\hline Ceftriaxone & 90.0 & 8.7 & 75.7 & 0.00 & 79.3 & 0.00 \\
\hline Ceftazidime & 87.1 & 1.7 & 61.8 & 3.9 & 34.5 & 1.8 \\
\hline Cefepime & 90.6 & 0.4 & 51.1 & 10.6 & 38.1 & 0.00 \\
\hline Cefoxitin & 100.0 & 0.0 & 58.3 & 0.00 & 0.00 & 0.00 \\
\hline Imipenem & 86.5 & 0.9 & 34.8 & 0.00 & 1.7 & 0.00 \\
\hline Tigecycline & 5.3 & 42.8 & 7.7 & 3.8 & 0.00 & 0.00 \\
\hline Gentamicin & 81.3 & 3.1 & 51.8 & 0.00 & 65.5 & 0.00 \\
\hline Amikacin & 47.1 & 1.3 & 31.6 & 0.00 & 6.9 & 0.00 \\
\hline Tobramycin & 79.4 & 1.2 & 51.8 & 0.00 & 65.5 & 0.00 \\
\hline Levofloxacin & 61.5 & 23.3 & 39.5 & 5.3 & 53.4 & 1.7 \\
\hline Ciprofloxacin & 86.8 & 0.0 & 40.0 & 7.0 & 55.2 & 8.6 \\
\hline $\begin{array}{l}\text { Trimethoprim/ } \\
\text { Sulfamethoxazole }\end{array}$ & 68.8 & 0.0 & 36.5 & 0.00 & 82.8 & 0.00 \\
\hline Nitrofurantoin & 100.0 & 0.0 & 44.0 & 40.0 & 5.2 & 5.2 \\
\hline Cefazolin & 100.0 & 0.0 & 79.7 & 0.00 & 82.9 & 4.9 \\
\hline Cefotetan & 100.0 & 0.0 & 34.7 & 0.00 & 0.00 & 7.8 \\
\hline
\end{tabular}

${ }^{a}$ Natural resistance.

tance to cefoperazone/sulbactam, tigecycline and amikacin. Klebsiella pneumoniae showed a considerable rate of resistance to most tested antibiotics and was highly susceptible to tigecycline. Escherichia coli showed a higher antimicrobial resistant rate for ampicillin, ampicillin/ sulbactam, ceftriaxone, gentamicin, tobramycin, trimethoprim/sulfamethoxazole, cefazolin and showed highly susceptible to cefoperazone/sulbactam, piperacillin/tazobactam, cefoxitin, imipenem, tigecycline, amikacin, nitrofurantoin and cefotetan (Table V).

\section{Antibiotic resistance rate of Cryptococcus neoformans (CN)}

All Cryptococcus neoformans were susceptible to 5-fluorocytosine and only $3.6 \% \mathrm{CN}$ were resistance to fluconazole. There are no approved interpretive breakpoints available for amphotericin $\mathrm{B}$, itraconazole and voriconazole (Table VI).
Table VI. Antibiotic resistance rate of Cryptococcus neoformans

\begin{tabular}{|lccc|}
\hline Antibiotic & $\mathrm{R}(\%)$ & $\mathrm{I}(\%)$ & $\mathrm{S}(\%)$ \\
\hline 5-Fluorocytosine & 0.0 & 0.0 & 100.0 \\
\hline Amphotericin B & $\mathrm{N}$ & $\mathrm{N}$ & $\mathrm{N}$ \\
\hline Fluconazole & 3.6 & 6.5 & 89.9 \\
\hline Itraconazole & $\mathrm{N}$ & $\mathrm{N}$ & $\mathrm{N}$ \\
\hline Voriconazole & $\mathrm{N}$ & $\mathrm{N}$ & $\mathrm{N}$ \\
\hline
\end{tabular}

Initial clinical and laboratory characteristics of study patients

The comparative results in the study patients infected with Coagulase-negative staphylococci (CNS), Acinetobacter baumanii and CN are listed in Table VII. The patients with Mycobacterium tuberculosis was too few for analysis. There was a statistically significant difference $(p<0.05)$ in head injury, invasive operation, fever, headache, 
Wei Chen, Qian Hu, Wen En Liu

Table VII. Initial clinical and laboratory characteristics of study patients infected with CNS, Ab and CN

\begin{tabular}{|c|c|c|c|c|c|}
\hline Parameter & CNS & $A B$ & $\mathrm{CN}$ & $\chi^{2}$ or $F$ & $P$-value \\
\hline Sex (male) & $34(68.0 \%)$ & $30(60.0 \%)$ & $29(58.0 \%)$ & $\chi^{2}=1.188$ & 0.552 \\
\hline Age [years] & $41.44 \pm 20.90$ & $44.06 \pm 17.39$ & $42.26 \pm 19.38$ & $F=0.241$ & 0.786 \\
\hline Days of hospital stay [days] & $31.84 \pm 25.42$ & $28.36 \pm 18.03$ & $37.32 \pm 33.09$ & $F=1.481$ & 0.231 \\
\hline Head injury & $9(18.0 \%)$ & $20(40.0 \%)$ & $1(2.0 \%)$ & $\chi^{2}=22.750$ & $<0.001$ \\
\hline Invasive operation & $35(70.0 \%)$ & $43(86.0 \%)$ & $2(4.0 \%)$ & $\chi^{2}=75.911$ & $<0.001$ \\
\hline Underlying diseases & $9(18.0 \%)$ & $6(12.0 \%)$ & $9(18.0 \%)$ & $\chi^{2}=0.893$ & 0.640 \\
\hline Bacteremia & $2(4.0 \%)$ & $5(10.0 \%)$ & $8(16.0 \%)$ & $\chi^{2}=4.000$ & 0.135 \\
\hline Fever & $23(46.0 \%)$ & $32(64.0 \%)$ & $35(70.0 \%)$ & $\chi^{2}=6.500$ & 0.039 \\
\hline Headache & $24(48.0 \%)$ & $9(18.0 \%)$ & $41(82.0 \%)$ & $\chi^{2}=41.021$ & $<0.001$ \\
\hline Nausea/vomiting & $13(26.0 \%)$ & $10(20.0 \%)$ & $27(54.0 \%)$ & $\chi^{2}=14.820$ & 0.001 \\
\hline Meningeal irritation signs & $22(44.0 \%)$ & $27(54.0 \%)$ & $24(48.0 \%)$ & $\chi^{2}=1.014$ & 0.602 \\
\hline Disturbance of consciousness & $21(42.0 \%)$ & $39(78.0 \%)$ & $2(4.0 \%)$ & $\chi^{2}=56.470$ & $<0.001$ \\
\hline $\begin{array}{l}\text { The pupil size of both eyes was not } \\
\text { equal }\end{array}$ & $7(14.0 \%)$ & $18(36.0 \%)$ & $1(2.0 \%)$ & $\chi^{2}=20.751$ & $<0.001$ \\
\hline $\begin{array}{l}\text { Pupillary reaction to light was slow } \\
\text { or absent }\end{array}$ & $18(36.0 \%)$ & $38(76.0 \%)$ & $3(6.0 \%)$ & $\chi^{2}=51.686$ & $<0.001$ \\
\hline Twitch & $5(10.0 \%)$ & $5(10.0 \%)$ & $2(4.0 \%)$ & $\chi^{2}=1.630$ & 0.443 \\
\hline $\begin{array}{l}\text { The prescribed antimicrobial } \\
\text { received }\end{array}$ & $41(82.0 \%)$ & $35(70.0 \%)$ & $8(16.0 \%)$ & $\chi^{2}=50.162$ & $<0.001$ \\
\hline $\begin{array}{l}\text { The prescribed immunosuppressant/ } \\
\text { hormone received }\end{array}$ & $23(46.0 \%)$ & $20(40.0 \%)$ & $7(14.0 \%)$ & $\chi^{2}=13.020$ & 0.001 \\
\hline CSF WBC counts $\left[\times 10^{6} / \mathrm{I}\right]$ & $550.73 \pm 1167.02$ & $2480.89 \pm 3902.39$ & $89.59 \pm 85.61$ & $F=14.129$ & $<0.001$ \\
\hline CSF polymorphonuclear cell ratio (\%) & $62.66 \pm 34.92$ & $79.24 \pm 27.10$ & $41.76 \pm 30.05$ & $F=14.901$ & $<0.001$ \\
\hline CSF glucose $[\mathrm{mmol} / \mathrm{l}]$ & $3.78 \pm 1.73$ & $1.81 \pm 3.30$ & $2.21 \pm 1.52$ & $F=15.272$ & $<0.001$ \\
\hline CSF protein concentration $[\mathrm{g} / \mathrm{l}]$ & $1.27 \pm 0.87$ & $2.03 \pm 1.09$ & $0.99 \pm 0.72$ & $F=17.258$ & $<0.001$ \\
\hline Peripheral blood WBC count $\left[\times 10^{9} / I\right]$ & $11.44 \pm 5.27$ & $13.07 \pm 6.22$ & $9.64 \pm 4.86$ & $F=5.653$ & 0.004 \\
\hline Peripheral blood PLT count $\left[\times 10^{9} / 1\right]$ & $255.14 \pm 159.72$ & $266.94 \pm 139.74$ & $244.64 \pm 141.47$ & 0.287 & 0.751 \\
\hline
\end{tabular}

nausea/vomiting, disturbance of consciousness, the pupil size of both eyes not being equal, pupillary reaction to light being slow or absent, CSF WBC counts, CSF polymorphonuclear cell ratio, CSF glucose concentration, CSF protein concentration, peripheral blood WBC counts, the prescribed antimicrobial received and the prescribed immunosuppressant/hormone received in the three groups.

Long duration of hospital stay (31.84 $\pm 25.42 \mathrm{vs.}$ $28.36 \pm 18.03$ vs. $37.32 \pm 33.09$ days, $p=0.231)$, fever $(46.0 \%$ vs. $64.0 \%$ vs. $70.0 \%, p=0.039)$ and meningeal irritation signs $(44.0 \%$ vs. $54.0 \%$ vs. $48.0 \%, p=0.602$ ) were common symptoms in the three groups. There was no statistically significant difference $(p>0.05)$ in sex, age, underlying diseases, bacteremia, twitch and peripheral blood PLT counts among the three groups.
When compared to the CNS infection group, head injury, disturbance of consciousness, the pupil size of both eyes not being equal, pupillary reaction to light being slow or absent, high CSF WBC counts, high ratio of CSF polymorphonuclear cell and high CSF protein concentration were more common in the $\mathrm{Ab}$ infection group, while headache was more common in the CNS infection group compared to the Ab infection group (Table VIII).

When compared to the $\mathrm{CN}$ infection group, head injury, invasive operation, disturbance of consciousness, the pupil size of both eyes not being equal, pupillary reaction to light being slow or absent, the prescribed antimicrobial received, the prescribed immunosuppressant/hormone received and higher ratio of CSF polymorphonuclear cell were more common in the CNS and Ab infection group. Fever, headache and nausea/vomiting 
were more common in the $\mathrm{CN}$ infection group compared to the CNS and Ab infection group. The CSF glucose in the CN infection group was lower than in the CNS infection group but higher than in the $A b$ infection group (Table IX).

\section{Discussion}

Central nervous system infections continue to afflict populations worldwide, especially due to their associations with mortality and long-term disability [16]. The prevalence rates for pathogens causing meningitis vary with time, geographical distribution, age, underlying medical or surgical conditions, and mode of infection [17, 18]. The rate of positive yield of pathogen meningitis in our study was $8.16 \%$, which was higher than the results of previous studies [19-21]. The male-tofemale ratio was $1.78: 1$ in our patients, indicating that males are prone to have meningitis. A similar sex discrepancy in meningitis can be found in other countries [22, 23]. The reasons for this may be the differences in the immune, endocrine and reproductive systems of males and females [24]. Almost all microbes that are pathogenic to human beings have a potential to cause meningitis, but a relatively small number of pathogens account for most cases, although the reasons for this association remain partly understood [25]. An obvious increase in Gram-positive pathogens isolated from the CSF specimens can be found in our study. Gram-positive pathogens were responsible for $71.71 \%$ of the total isolates. The ratio of Gram-positive pathogens to Gram-negative pathogens was about 3.52 : 1, which appeared much higher than that observed in studies from other countries [19, 20, 26]. Reasons for this difference may include population differences in colonization, genetic differences in immune response and possibly geographic differences in laboratory techniques for pathogen isolation and reporting [27]. Staphylococcal, streptococcal and enterococcal bacteria were the common ones among Gram-positive pathogens, which were the common Gram-positive pathogens in other reports [7, 28, 29]. This finding highlights that treatment and management programs have been designed to address these bacteria. The reason for the low

Table VIII. $\chi^{2}$ segmentation method

\begin{tabular}{|c|c|c|c|c|c|c|}
\hline \multirow[t]{2}{*}{ Variable } & \multicolumn{2}{|c|}{ CNS vs. $A B$} & \multicolumn{2}{|c|}{ CNS vs. CN } & \multicolumn{2}{|c|}{$A B$ vs. $C N$} \\
\hline & $\chi^{2}$ value & $P$-value & $\chi^{2}$ value & $P$-value & $\chi^{2}$ value & $P$-value \\
\hline Head injury & 5.877 & 0.015 & 7.111 & 0.008 & 21.760 & $<0.001$ \\
\hline Invasive operation & 3.730 & 0.053 & 46.718 & $<0.001$ & 67.919 & $<0.001$ \\
\hline Fever & 3.273 & 0.070 & 5.911 & 0.015 & 0.407 & 0.523 \\
\hline Headache & 10.176 & 0.001 & 12.703 & $<0.001$ & 40.960 & $<0.001$ \\
\hline Nausea/vomiting & 0.508 & 0.476 & 8.167 & 0.004 & 12.398 & $<0.001$ \\
\hline Disturbance of consciousness & 13.500 & $<0.001$ & 20.384 & $<0.001$ & 56.594 & $<0.001$ \\
\hline The pupil size of both eyes was not equal & 6.453 & 0.011 & 4.891 & 0.027 & 18.778 & $<0.001$ \\
\hline $\begin{array}{l}\text { Pupillary reaction to light was slow or } \\
\text { absent }\end{array}$ & 16.234 & $<0.001$ & 13.562 & $<0.001$ & 50.641 & $<0.001$ \\
\hline The prescribed antimicrobial received & 1.974 & 0.160 & 43.577 & $<0.001$ & 29.743 & $<0.001$ \\
\hline $\begin{array}{l}\text { The prescribed immunosuppressant/ } \\
\text { hormone received }\end{array}$ & 0.367 & 0.545 & 12.190 & $<0.001$ & 8.574 & 0.003 \\
\hline
\end{tabular}

The redefined $P$ level was $0.0167(0.05 \div 3=0.0167)$ after Bonferroni correction.

Table IX. LSD t-test

\begin{tabular}{|lcccccc|}
\hline Parameter & \multicolumn{2}{c}{ CNS vs. AB } & \multicolumn{2}{c|}{ CNS vs. CN } & \multicolumn{1}{c|}{ AB vs. CN } \\
\cline { 2 - 6 } & $T$-value & $P$-value & $T$-value & $P$-value & $T$-value & $P$-value \\
\hline CSF WBC count $\left[\times 10^{6} / \mathrm{l}\right]$ & 4.038 & $<0.001$ & 0.975 & 0.331 & 5.029 & $<0.001$ \\
\hline CSF polymorphonuclear cell ratio (\%) & 2.305 & 0.023 & 2.853 & 0.005 & 5.454 & $<0.001$ \\
\hline CSF glucose $[\mathrm{mmol} / \mathrm{l}]$ & 5.185 & $<0.001$ & 4.216 & $<0.001$ & 1.035 & 0.302 \\
\hline CSF protein concentration $[\mathrm{g} / \mathrm{l}]$ & 4.192 & $<0.001$ & 1.519 & 0.131 & 5.688 & $<0.001$ \\
\hline Peripheral blood WBC counts $\left[\times 10^{9} / \mathrm{l}\right]$ & 1.596 & 0.113 & 1.764 & 0.080 & 3.360 & 0.001 \\
\hline
\end{tabular}


identification of Streptococcus pneumoniae, which has been reported as the most common cause of bacterial meningitis [30, 31], could be that less attention is given to the laboratory diagnosis of this pathogen. Gram-negative bacilli usually cause meningitis after head trauma or neurosurgery. $A b$, $\mathrm{KP}$ and Ec were common etiological agents of meningitis, which is in accordance with most of the published studies [32-34]. Therefore the epidemiologic changes in meningitis should alter clinicians' behavior regarding antibiotic prescription $[35,36]$.

There should be no delay in starting appropriate empiric antibiotics once the bacterial or fungal meningitis is suspected, and this requires knowledge of the likely pathogens and their antibiotic susceptibilities. Antibiotics such as linezolid, vancomycin, Quinupristin/Dalfopristin syncercid, tigecycline and nitrofurantoin were found to be most effective against staphylococcal meningitis. Penicillin G, oxacillin, clindamycin and erythromycin were the least effective antibiotics against the staphylococcal isolates. Therefore, the choice of vancomycin or linezolid as the antimicrobial agent for staphylococcal infection-related meningitis was required. Vancomycin is recommended for methicillin-resistant staphylococcal meningitis. Linezolid may be chosen in cases of vancomycin resistance ( $\mathrm{MIC}>2 \mu \mathrm{g} / \mathrm{ml}$ ) or in cases of contraindications to vancomycin [37]. Rifampicin could also be considered as supplementary therapy together with vancomycin or linezolid. Rifampicin must not be used as monotherapy to avoid the development of resistance [38].

After identification of the pathogen through culture and antibiotic susceptibility testing, the antibiotic treatment can be optimized. Linezolid, vancomycin, ofloxacin, meropenem and ertapenem were found to be the most effective drugs against Streptococcus pneumoniae. Reduced susceptibility to penicillin and third-generation cephalosporins of Streptococcus pneumoniae is a growing problem in China although resistance rates vary considerably between countries [2]. Some experts advise that when Streptococcus pneumoniae has been identified and susceptibility testing is pending or not available, empiric treatment should include vancomycin or rifampicin, although there is uncertainty regarding the benefit of adding vancomycin or rifampicin to a third-generation cephalosporin in Streptococcus pneumoniae meningitis patients [39-41]. Erythromycin, tetracycline, clindamycin, penicillin and trimethoprim/sulfamethoxazole were the least effective antibiotics against Streptococcus pneumoniae. By contrast, a higher resistance rate (92.1\%) to macrolide antibiotics was also reported by Tsai et al. from Taiwan [42]. The increased rate of macrolide antibiotics resistance can possibly be correlated with the wide use of this antibiotic in the communities because of its dose convenience, cost effectiveness, easy availability and the practice of prescribing it to treat suspected bacterial pneumonia cases.

Third-generation cephalosporin-resistant strains have become increasingly common in our study, which was also found in recent studies [43-45]. The resistance of $\mathrm{Ab}$ and $\mathrm{KP}$ to ceftriaxone/ceftazidime was $90.0 \% / 87.1 \%$ and $75.7 \% / 61.8 \%$, which is in accordance with the other studies $[35,46]$. The third-generation cephalosporins have been widely used for the treatment of patients with meningitis for their penetrance well into the CSF after intravenous administration and have resulted in a dramatic decrease in meningitis-related mortality [47]. The increasing number of third-generation cephalosporin-resistant Gram-negative pathogens not only challenges the existing therapeutic options for serious central nervous system infection but also influences the choice of empiric antibiotics. Empiric use of antibiotics requires clinical decision-making taking into account both the risk of the antibiotics not being covered appropriately for a certain pathogen and the risks associated with the overuse of antibiotics. Based on this study, empiric use of third-generation cephalosporins should be reassessed in patients with meningitis, and it would be sensible to initiate further studies of other potentially effective agents such as carbapenem as the early empiric therapy, although there need to be further investigations to ensure that the empiric use of carbapenem can improve the survival of patients with meningitis.

In bacterial and fungal meningitis, clinical deterioration can occur rapidly and is often difficult to predict [48]. The decision to commence antibiotics is often based on clinical symptoms as well as on the preliminary CSF results, which are readily available within an hour. In our current study, we investigated the differences in the initial clinical and laboratory findings between patients associated with CNS, Ab and CN. Multiple studies have shown that headache, fever and neck stiffness were common signs and symptoms in patients with bacterial meningitis [1, 18, 49-51]. Our study also showed that fever and meningeal irritation signs were common symptoms in the three groups. Head injury, invasive operation, fever, headache, nausea/vomiting, disturbance of consciousness, the pupil size of both eyes not being equal, pupillary reaction to light being slow or absent, the prescribed antimicrobial received and the prescribed immunosuppressant/hormone received were predictive of a diagnosis of meningitis. Several studies have confirmed these findings [52-54]. In our study, of these factors, only head injury, headache, disturbance of conscious- 
ness and pupillary reaction to light being slow or absent were significantly different among the three groups. Fever, headache and nausea/vomiting were more common in the $\mathrm{CN}$ infection group compared to the other two groups. Head injury, disturbance of consciousness, the pupil size of both eyes not being equal, and pupillary reaction to light being slow or absent were more common in the Ab infection group compared to the other two groups.

Another study noted that the extent of CSF abnormalities depends on the causative microorganism and can assess the cause of suspected meningitis [40]. Our study tried to assess the utility of CSF WBC, protein and glucose concentration in assessing the cause of suspected meningitis. There was a significant difference between the CSF parameters in Ab meningitis compared to CNS and CN meningitis. Abnormalities of CSF composition in $\mathrm{Ab}$ meningitis include pleocytosis of mainly polymorphic leukocytes, low glucose concentration and elevated protein levels. Abnormalities of CSF composition in CN meningitis are high WBC of normal polymorphic leukocytes, low glucose concentration and high protein levels. Abnormalities of CSF composition in CNS meningitis are high WBC of mainly polymorphic leukocytes, a normal glucose concentration and high protein levels. This is in accordance with some studies indicating that high CSF WBC counts, high ratio of CSF polymorphonuclear cells, high CSF protein concentration and low CSF glucose concentration indicate a potential diagnosis of bacterial meningitis when compared to $\mathrm{CN}$ and viral meningitis [1, $55,56]$. A previous study also showed that glucose levels lower than $1.81 \mathrm{mmol} / \mathrm{l}$, protein levels over $2.03 \mathrm{~g} / \mathrm{l}$ and leukocyte count over 2480 cells $/ \mathrm{mm}^{3}$ are individual predictors of bacterial meningitis [56]. Some study have shown that both CSF protein concentration and WBC have a low specificity for distinguishing the cause of meningitis. However, this does not preclude clinical use of these CSF parameters, as definitive testing would be indicated even if a high specificity had been found. This study provides evidence that in cases of suspected meningitis, the CSF protein concentration and WBC as well as glucose concentration can be used in guiding initial treatment and further microbiological investigation.

Certain limitations and problems should be noted. First, we did not record cases of clinical meningitis without positive cultures of CSF as well as viral meningitis, which were difficulties encountered in conducting studies assessing disease in developing countries such as China. Second, our data were from a single hospital, so they are unlikely to represent the exact epidemiology of the whole area. Third, the hospital-based studies determining etiologies of meningitis were conducted in academic tertiary hospitals where patients were likely to exhibit more severe and high previous antibiotic usage in the early stage of disease, which could lower the culture positive rate. Finally, there are few small towns and rural patients arrive who at this hospital were the main component of community-acquired bacterial meningitis; thus our data may not be representative of the spectrum of diseases in the population.

In conclusion, a variety of Gram-positive as well as Gram-negative organisms was documented. This situation calls for the longitudinal nation-wide surveillance for meningitis to document the real scenario regarding prevalent strains of pathogens. The selection of empiric antibiotics should take into consideration local epidemiology, antibiotic resistance patterns and the suspected causative microorganism according to the initial clinical and laboratory characteristics of patients. Early and focused treatment of the established disease is vital and further investigates into optimum empirical antibiotic therapy is needed.

\section{Conflict of interest}

The authors declare no conflict of interest.

\section{References}

1. van de Beek D, de Gans J, Spanjaard L, et al. Clinical features and prognostic factors in adults with bacterial meningitis. N Engl J Med 2004; 351: 1849-59.

2. van de Beek D, Brouwer MC, Thwaites GE, et al. Advances in treatment of bacterial meningitis. Lancet 2012; 380: 1693-702.

3. World Health Organization (WHO) meningitis manual: Laboratory Methods for the Diagnosis of Meningitis caused by Neisseria meningitidis, Streptococcus pneumoniae, and Haemophilus influenzae, second edition, 2011.

4. Okike IO, Ribeiro S, Ramsay ME, et al. Trends in bacterial, mycobacterial, and fungal meningitis in England and Wales 2004-11: an observational study. Lancet Infect Dis 2014; 14: 301-7.

5. Thornorethardottir A, Erlendsdottir H, Sigurethardottir B, et al. Bacterial meningitis in adults in Iceland, 1995-2010. Scand J Infect Dis 2014; 46: 354-60.

6. Moon SY, Chung DR, Kim SW, et al. Changing etiology of community-acquired bacterial meningitis in adults: a nationwide multicenter study in Korea. Eur J Clin Microbiol Infect Dis 2010; 29: 793-800.

7. Chang WN, Lu CH, Huang CR, et al. Changing epidemiology of adult bacterial meningitis in southern Taiwan: a hospital-based study. Infection 2008; 36: 15-22.

8. Thomson RB Jr, Bertram H. Laboratory diagnosis of central nervous system infections. Infect Dis Clin North Am 2001; 15: 1047-71.

9. Kamei, S. Bacterial meningitis: determination of pathogens and therapeutic management. Clin Neuro 2004; 44: 846-8.

10. Nemeth J, Oesch G, Kuster SP. Bacteriostatic versus bactericidal antibiotics for patients with serious bacterial 
infections: systematic review and meta-analysis. J Antimicrob Chemother 2015; 70: 382-95.

11. Morita A. Clinical and laboratory diagnosis of central nervous system infections. Brain Nerve 2015; 67: 777-85.

12. Sussmuth SD, Brettschneider J, Spreer A, et al. Current cerebrospinal fluid diagnostics for pathogen-related diseases. Der Nervenarzt 2013; 84: 229-44.

13. Philip N, William T, William DV. Diagnosis of tuberculous meningitis: challenges and promises. Malaysian J Pathol 2015; 37: 1-9.

14. Furyk JS, Swann O, Molyneux E. Systematic review: neonatal meningitis in the developing world. Trop Med Int Health 2011; 16: 672-9.

15. Clinical and Labooratory Standards Institute (CLSI). Performance stands for antimicrobial susceptibility testing [S]. M100S, 2016.

16. Sundaram C, Shankar SK, Thong WK, Pardo-Villamizar CA. Pathology and diagnosis of central nervous sys tem infections. Patholog Res Int 2011; 2011: 8782-63.

17. Durand ML, Calderwood SB, Weber DJ, et al. Acute bac terial meningitis in adults: a review of 493 episodes. N Engl J Med 1993; 328: 21-8.

18. Sigurardottir B, Bjornsson OM, Jonsdottir KE, et al. Acute bacterial meningitis in adults: a 20-year overview. Arch Intern Med 1997; 157: 425-30.

19. Ghotaslou R, Farajnia S, Yeganeh F, et al. Detection of acute childhood meningitis by PCR, culture and agglutination test at Tabriz, Iran. Acta Med Iran 2012; 50: 192-6.

20. Rezaeizadeh G, Pourakbari B, Ashtiani MH, et al. Antimicrobial susceptibility of bacteria isolated from cerebrospinal fluids in an Iranian referral pediatric center, 1998-2008. Maedica (Buchar) 2012; 7: 131-7.

21. Zamani A, Zamani F. Cerebrospinal fluid findings in neonatal bacterial meningitis. MJIRI 2005; 19: 241-5.

22. Shinjoh M, Iwata S, Sato Y, et al. Childhood bacterial meningitis trends in Japan from 2009 to 2010. Kansenshogaku Zasshi 2012; 86: 582-91.

23. McCormick DW, Wilson ML, Mankhambo L, et al. Risk factors for death and severe sequelae in Malawian children with bacterial meningitis, 1997e2010. Pediatr Infect Dis J 2013; 32: e54-61.

24. Eshima N, Tokumaru O, Hara S, et al. Age-specific sex-related differences in infections: a statistical analysis of national surveillance data in Japan. PLoS One 2012; 7: e42261.

25. Thigpen MC, Whitney CG, Messonnier NE, et al. Bacterial meningitis in the United States, 1998-2007. N Engl J Med 2011; 364: 2016-25.

26. San Gabriel P, Zhou J, Tabibi S, et al. Antimicrobial susceptibility and synergy studies of Stenotrophomonas maltophilia isolates from patients with cystic fibrosis. Antimicrob Agents Chemother 2004; 48: 168-71.

27. Arda B, Sipahi OR, Atalay S, et al. Pooled analysis of 2,408 cases of acute adult purulent meningitis from Turkey. Med Princ Pract 2008; 17: 76-9.

28. Peňa C, Suarez C, Tubau F, et al. Nosocomial outbreak of a non-cefepime-susceptible ceftazidime-susceptible Pseudomonas aeruginosa strain over expression MexXY-OprM and producing an integron-borne PSE-1 beta-lactamase. J Clin Microbiol 2009; 47: 2381-7.

29. Tsai TN, Wu CP, Peng MY, et al. Short course of linezolid treatment for vancomycin-resistant Enterococcus faecium meningitis. Int J Clin Pract 2006; 60: 740-1.

30. Ludwig E, Unal S, Bogdan $M$, et al. Opportunity for healthy ageing: lessening the burden of adult pneumococcal disease in Central and Eastern Europe, and Israel. Cent Eur J Public Health 2012; 20: 121-5.
31. Spiro CE, Spiro DM. Acute meningitis: focus on bacterial infection. Clin Rev 2014; 14: 53-60.

32. Lu CH, Chang WN, Chuang YC, Chang HW. Gram-negative bacillary meningitis in adult post-neurosurgical patients. Surg Neurol 1999; 52: 438-43.

33. Lu CH, Chang WN, Chuang YC, Chang HW. The prognostic factors of adult Gram-negative bacillary meningitis. J Hosp Infect 1998; 40: 27-34.

34. Lu CH, Chang WN, Chang HW. Adult bacterial meningitis in southern Taiwan: epidemiologic trend and prognostic factors. J Neurol Sci 2000; 182: 36-44.

35. Tunkel AR, Hartman BJ, Kaplan SL, et al. Practice guidelines for the management of bacterial meningitis. Clin Infect Dis 2004; 39: 1267-84.

36. Beckham JD, Tyler KL. Initial management of acute bacterial meningitis in adults. Rev Neurol Dis 2006; 3: 57-60.

37. Brouwer MC, Tunkel AR, van de Beek D. Epidemiology, diagnosis, and antimicrobial treatment of acute bacterial meningitis. Clin Microbiol Rev 2010; 23: 467-92.

38. van de Beek D, Cabellos C, Dzupova O, et al. ESCMID guideline: diagnosis and treatment of acute bacterial meningitis. Clin Microbiol Infect 2016; 22 Suppl 3: S37-62.

39. Suntur BM, Yurtseven T, Sipahi OR, et al. Rifampicin + ceftriaxone versus vancomycin + ceftriaxone in the treatment of penicillin- and cephalosporin-resistant pneumococcal meningitis in an experimental rabbit model. Int J Antimicrob Agents 2005; 26: 258-60.

40. Lee $\mathrm{H}$, Song JH, Kim SW, et al. Evaluation of a triple-drug combination for treatment of experimental multidrugresistant pneumococcal meningitis. Int J Antimicrob Agents 2004; 23: 307-10.

41. Friedland IR, Paris M, Ehrett $S$, et al. Evaluation of antimicrobial regimens for treatment of experimental penicillin and cephalosporin-resistant pneumococcal meningitis. Antimicrob Agents Chemother 1993; 37: 1630-6.

42. Tsai HY, Lauderdale TL, Wang JT, et al. Updated antibiotic resistance and clinical spectrum of infections caused by Streptococcus pneumoniae in Taiwan: emphasis on risk factors for penicillin nonsusceptibilities. J Microbio Immunol Infect 2013; 46: 345-51.

43. Chen SF, Chang WN, Lu CH, et al. Adult Acinetobacter meningitis and its comparison with non-acinetobacter bacterial meningitis. Acta Neurol Taiwan 2005; 14: 125-9.

44. Huang CR, Lu CH, Chuang YC, et al. Adult Pseudomonas aeruginosa meningitis: high incidence of underlying medical and/or postneurosurgical conditions and high mortality rates. Jpn J Infect Dis 2007; 60: 397-9.

45. Chang CJ, Ye JJ, Yang CC, et al. Influence of third-generation cephalosporin resistance on adult in-hospital mortality from post-neurosurgical bacterial meningitis. J Microbiol Immunol Infect 2010; 43: 301-9.

46. Marion DW. Complications of head injuries and their therapy. Neurosurg Clin N Am 1991; 2: 411-24.

47. Landesman SH, Cherubin CE, Corrado ML. Gram-negative bacillary meningitis: new therapy and changing concepts. Arch Intern Med 1982; 142: 939-40.

48. van de Beek D, de Gans J. Dexamethasone in adults with community-acquired bacterial meningitis. Drugs 2006; 66: 415-27.

49. Bodilsen J, Dalager-Pedersen M, Schonheyder HC, Nielsen $\mathrm{H}$. Dexamethasone treatment and prognostic factors in community acquired bacterial meningitis: a Danish retrospective population based cohort study. Scand J Infect Dis 2014; 46: 418-25.

50. Dauchy FA, Gruson D, Chene G, et al. Prognostic factors in adult community-acquired bacterial meningitis: a 4-year retrospective study. Eur J Clin Microbiol Infect Dis 2007; 26: 743-6. 
51. Domingo P, Pomar V, Benito N, Coll P. The changing pattern of bacterial meningitis in adult patients at a large tertiary university hospital in Barcelona, Spain (19822010). J Infect 2013; 66: 147-54.

52. Moghtaderi A, Alavi-Naini R, Izadi S, Cuevas LE. Diagnostic risk factors to differentiate tuberculous and acute bacterial meningitis. Scand J Infect Dis 2009; 41: 188-94.

53. Youssef FG, Afifi SA, Azab AM, et al. Differentiation of tuberculous meningitis from acute bacterial meningitis using simple clinical and laboratory parameters. Diagn Microbiol Infect Dis 2006; 55: 275-8.

54. Vibha D, Bhatia R, Prasad K, et al. Validation of diagnostic algorithm to differentiate between tuberculous meningitis and acute bacterial meningitis. Clin Neurol Neurosurg 2002; 114: 639-44.

55. Spanos A, Harrell Jr FE, Durack DT. Differential diagnosis of acute meningitis. An analysis of the predictive value of initial observations. JAMA 1989; 262: 2700-7.

56. Heckenberg SG, Brouwer MC, van der Ende A, van de Beek D. Adjunctive dexamethasone in adults with meningococcal meningitis. Neurology 2012; 79: 1563-9. 